\title{
Fine-grained concrete with organomineral additive
}

\author{
Vitaly Solovyov ${ }^{1 *}$ and Yulia Sokolova ${ }^{2}$ \\ ${ }^{1}$ Moscow State University of Civil Engineering, 129337, Yaroslavskoye Shosse 26, Moscow, Russia \\ ${ }^{2}$ NOU INEP, 115477, Bekhtereva ul, d 13, korp 3, Moscow, Russia
}

\begin{abstract}
The article deals with the issues concerning the formation of the structure and properties of fine-grained concrete with organomineral additive produced through mechanochemical activation of thermal power plant fly ash together with superplasticizer. The additive is produced in a high-speed activator at the collision particles' speed of about $80 \mathrm{~m} / \mathrm{s}$. The use of the additive in fine-grained concrete in the amounts of $0.5-1 \%$ increased the strength by $30-50 \%$ and reduced the size and volume of pores. The cement consumption in such concrete is close to the cement consumption in common concrete of equal resistance.
\end{abstract}

\section{Introduction}

The thermal power plant fly ash with the following chemical composition was used for the research: $\mathrm{SiO} 2-40 \ldots 58 \%, \mathrm{Al} 2 \mathrm{O} 3-21 \ldots 27 \%, \mathrm{CaO}-4 \ldots 6 \%, \mathrm{Fe} 2 \mathrm{O} 3-4 \ldots 17 \%$, NaO$0.4 \ldots 1.4 \%, \mathrm{~K} 2 \mathrm{O}-0.4 \ldots .7 .7 \%$.

Moreover, the composition of the fly ash included, among others, small amounts of SO3, $\mathrm{MgO}$ and $\mathrm{TiO} 2$.

Highly-homogeneous, chemically active and law water demand nanomodified organomineral additive was produced through mechanochemical activation in a high-speed activator with an annular processing chamber at the speed of impact of material particles of about $80 \mathrm{~m} / \mathrm{s}$.

This includes not only grinding of materials, but also change of physical and chemical state and structure.

The crystal lattice is disturbed and transformed up to its transition to amorphous state. Such modification is accompanied by an increase in the specific area and increase in the surface energy of the substance.

The grain size composition of the activated fly ash with the presence of $0.3 \% \mathrm{~S}-3$ superplasticizer,obtained with the use of a laser granulometer, is shown on Fig.1.

The analysis of the grain size composition of the mechanochemically activated fly ash shows that it contains particles with a size of less than 10-6 m.

The number of particles of less than $500 \mathrm{~nm}$ amounts to $2.06 \%$ and that of the 500 to $1000 \mathrm{~nm}$ particles amounts to $3.12 \%$.

\footnotetext{
* Corresponding author: sotae@mgsu.ru
} 


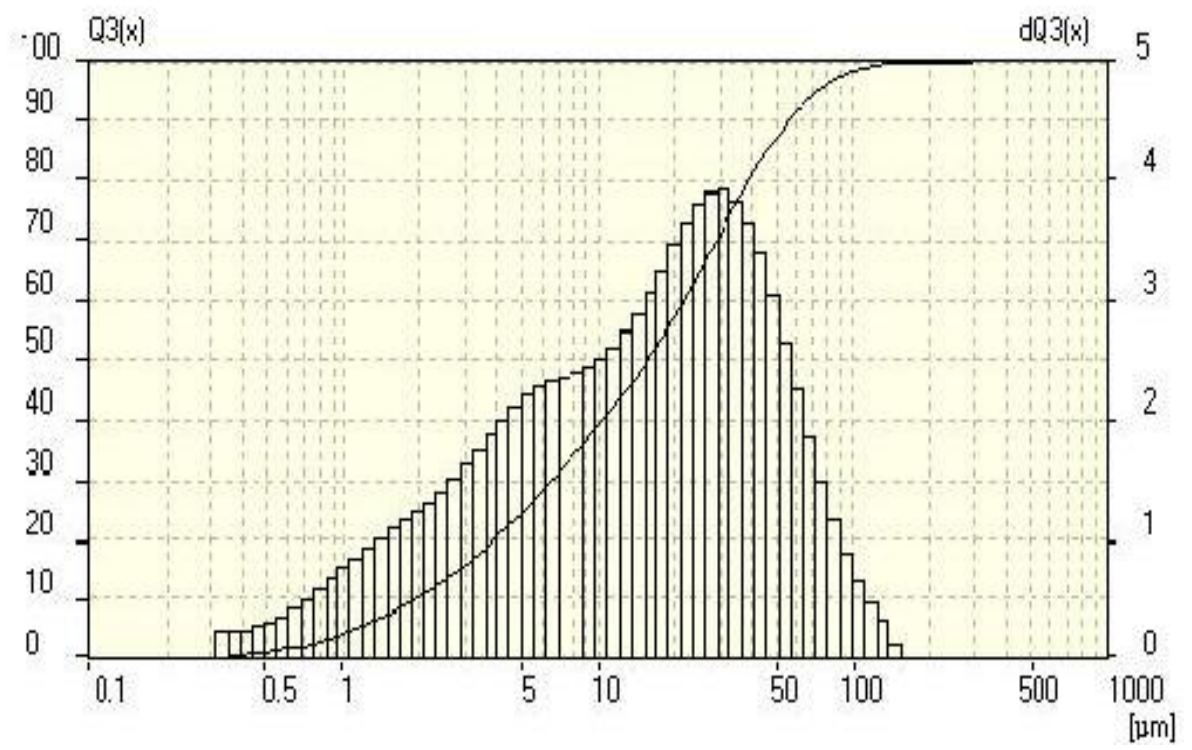

Fig.1. The integral and differential distribution of particles based on the size of mechanoactivated fly ash

The additive was tested in fine-grained concrete (FGC) prepared on the basis of PTsD0 M500 Portland cementand silica sand by weight proportion of 1:2, with the mobility determined on a standard shaker apparatus, and with a spread diameter of $17 \mathrm{~cm}$.

$4 \times 4 \times 16 \mathrm{~cm}$ samples steam cured under the following regime: $3+3+5$ at $80^{\circ} \mathrm{C}$ with isothermal warming were made.

The physical and mechanical characteristics of the obtained test resultsare shown in the table 1 .

Table 1. Physical and mechanical properties of FGC on the basis of multicomponent binders.

\begin{tabular}{|c|l|c|c|c|c|}
\hline \multirow{2}{*}{ item \# } & \multirow{2}{*}{ Binder composition } & \multicolumn{2}{|c|}{ Bending strength } & \multicolumn{2}{c|}{ Compression strength, } \\
\cline { 3 - 6 } & & $\mathrm{MPa}$ & $\%$ & $\mathrm{MPa}$ & $\%$ \\
\hline 1 & PTs & 6.0 & 100.0 & 32.2 & 100.0 \\
\hline 2 & PTs $+25 \%$ AF & 5.65 & 94.2 & 32.0 & 99.4 \\
\hline 3 & PTs + 40 \% AFwith SP & 5.97 & 99.5 & 48.4 & 150.3 \\
\hline 4 & PTs + 25 \% AFwith SP & 5.76 & 96.0 & 41.6 & 129.2 \\
\hline 5 & PTs + AF $(1: 1)$ & 5.96 & 99.3 & 34.4 & 106.8 \\
\hline
\end{tabular}

Note: AF means activated fly ash

In the context of impact on concrete, fly ash is an active mineral additive; moreover, it fulfills the function of a filler making the concrete denser.

In the process of curing, beside the pozzolanic reaction, amorphous silica and aluminium oxide interreact with calcium hydroxide produced from cement hydration, which results in the formation of law-basic hydrosilicates and calcium hydroaluminates $[7,8]$.

This not only contributes to better strength and density, but to longer life of nanomodified fine-grained concrete. 


\section{Conclusion}

The research carried out shows that the application of nanomodifiers on the basis of mechanoactivated fly ash in the amount of $0.5-1 \%$ has a positive influence on the structure and on physical and mechanical properties of fine-grained concrete, since it contributes to a $35-40 \%$ reduction of cement consumption and $30-50 \%$ increase in the strength.

\section{References}

1. L.A. Alimov, V.V. Voronin, Construction materials (Textbook. Publishing center, Academia, 2012)

2. L.A. Alimov, V.V. Voronin, Concrete work technology (Textbook, Publishing center, Academiya, 2015)

3. Yu.M. Bazhenov, Compilation of roundtable presentations, 12-18 (MGSU, 2007)

4. Yu.M. Bazhenov, L.A. Alimov, V.V. Voronin, Structure and properties of concrete with nanomodifiers on the basis of technogenic waste (Nomografiya, EBSASV, 2013)

5. L.A. Alimov, V.V. Voronin, A.A. Buldyzhov, I.V. Romanov, Mag. Nauchnoe obozrenie, 9, 177-181 (2013)

6. L.A. Alimov, S.I. Bazhenova, Vestnik MGSU, 1 (2010)

7. Yu.M. Bazhenov, L.A. Alimov, V.V. Voronin, A.A. Buldyzhov, I.V. Romanov, Patent 2474544 dated 10.02.2013 Method for preparation of a nanomodifier from industrial waste for concrete mix.

8. G. Quercia, J.J.G. van der Putten, G. Hüsken, H.J.H. Brouwers, Orig. Res. Art. Cement and Conc. Res., 54, 161-179 (2013)

9. A. Krishan, V. Rimshin, V. Erofeev, V. Kurbatov, S. Markov, Pr. Eng., 117, 211-217 (2015)

10. V. Semenov, A. Pligina, T. Rozovskaya, IOP Conference Series: Materials Science and Engineering, 71, art. no. 012041 (2015)

11. A. Tamrazyan, App. Mech. and Mat., 475-476, 1563-1566 (2014)

12. A.S. Inozemtcev, E.V. Korolev, Adv. in Cem. Res., 28, $92-98$ (2016)

13. A.S. Inozemtcev, IOP Conference Series: Materials Science and Engineering, 71 (2015)

14. A. Adamtsevich, A. Pustovgar, S. Pashkevich, A. Eremin, A. Zhuravlev, App. Mech. and Mat., 670-671, 339-343 (2014)

15. V.A. Perfilov, D.V. Oreshkin, D.Y. Zemlyanushnov, Pr. Eng., 150, 1474-1478 (2016)

16. L.N. Rasskazov, A.V. Radzinskii, M.P. Sainov, Power Tech. and Eng., 48, 358-360 (2015) 